\title{
Noise Levels in Urban and Rural Settlements of Bhubaneswar: A Case Study
}

\author{
G. Ayush*, A. J. Elizabeth*, V. V. Patil*† and M. Herlekar** \\ *School of Sustainability, XIM University, Bhubaneswar, Harirajpur-752 050, Odisha, India \\ **Department of Environmental Science, The Institute of Science, Dr. Homi Bhabha State University, Mumbai-400 032, \\ Maharashtra, India \\ †Corresponding author: V. V. Patil; vikrant@xim.edu.in
}

Nat. Env. \& Poll. Tech.

Website: www.neptjournal.com

Received: 10-06-2021

Revised: 29-06-2021

Accepted: 14-07-2021

\section{Key Words:}

Noise

Health

GIS

Urban and rural settlements

\section{ABSTRACT}

Noise is an underestimated threat that can cause several short- and long-term health problems. It is increasingly becoming a potential hazard to health, physically and psychologically, and affects the general well-being of an individual. The objective of the current study was to examine noise levels at ten different locations in the city of Bhubaneswar, Odisha State, India based on the land use pattern in urban and rural setup. The paper focuses on deploying geospatial techniques using ArcGIS desktop to perform better sampling and further interpolate the statistical data using the Kriging technique to generate a surface representing the distribution of noise levels in various areas. In addition, a health impact survey enabled us to understand the perspectives of the people in and around the monitoring location where health issues like stress, headache, hypertension, and sleeping disorders emerged as some of the most common issues faced. Noise levels were in the range of 43.0 to $74.5(\mathrm{~A})$ Leq. in rural areas and 61 to $96.5 \mathrm{~dB}(\mathrm{~A})$ Leq in urban areas. In the current study, noise levels in rural and urban areas exceeded the recommended noise limits as per The Noise Pollution (Regulation and Control) Rules, 2000.

\section{INTRODUCTION}

Sound occurs due to changes in air pressure inside the ear canal that cause our inner ears to vibrate and produces the auditory sensations which our brain interprets as sound. Noise pollution is any unwanted or disturbing sound that harms the health and well-being of humans and wildlife (Jain et al. 2015). This type of interference often causes discomfort in residents, which sometimes ends up being hazardous. The effects of noise are seldom catastrophic and are often only transitory, but adverse effects can be cumulative with prolonged or repeated exposure and can significantly impair the quality of life (Capetown, n.d.).

Noise is an undervalued danger causing a lot of shortand long-term health problems (WHO n.da). Noise exposure among vulnerable groups, such as children, is an area of major concern (Jamir et al. 2014, Khatik et al. 2019). Excessive noise interferes with people's daily activities at work, school, home, and leisure time. It can disturb sleep, cause cardiovascular and psychophysiological effects, reduce performance, and provoke annoyance responses and social behavior changes (WHO n.db). Since there are direct links between noise and health, identifying sources of loud noise will assist the administration to abate high noise problematic areas, thus becoming compliant with city and other noise criteria and ordinances as defined by CPCB (2010).
Several studies in the recent past indicate that noise levels have crossed the set limits in India. 27 sites were monitored for noise level around a sensitive zone for 24 hours (Khaiwal et al. 2016). It included various categories viz. outdoor, indoor, road, and residential areas. The noise level ranged from $45 \mathrm{~dB}$ to as high as $120 \mathrm{~dB}$ exceeding the prescribed daytime standard for the sensitive zone. Further, a pan India study was conducted at 35 locations between 2011 and 2014 (Garg et al. 2017). These 35 locations were distributed among commercial zone (14 locations), Industrial (5 locations), residential (7 Locations), and the silence zone (9 Locations). This study was constructive in ascertaining the magnitude of annual average ambient noise levels, noise abatement action plans, and the formulation of revised ambient noise standards in Indian scenarios. Further noise levels were measured at 227 sites of Malda, West Bengal, India, covering major roads, some important nodes, railway stations, bus stops, rail crossing, commercial area, and residential area (Das et al. 2019). The recorded noise levels varied between $25 \mathrm{~dB}$ to 83 $\mathrm{dB}$. The study concluded that noise annoyance is sensitive to age, sex, economic folks, and facing the window to the road. Out of the total study area, $9.94 \%$ area has emerged as the most vulnerable area to noise exposition.

Bhubaneswar's foremost challenges include rapid unplanned development, especially construction, increasing pollution from vehicles and commercial establishments, 
road dust and other fugitive emissions, and significantly higher noise levels (Bisht 2021). In India, though noise levels are measured at the community level, limited studies have been published on the health effects of noise levels (Jamir et al. 2014). With this background, the research focuses on monitoring noise levels in rural and urban settlements of Bhubaneswar city. The data is further analyzed statistically and geographically to generate noise pollution maps. Noise mapping is one of the new methods to assess noise levels, and it helps plan to control noise pollution effects (Olayinka 2013). Several studies have warranted the importance of GIS-based noise mapping to make informed decisions related to its management. GIS can be beneficial in identifying the noise intensity, building density, and spatial layouts of the buildings (Yuan et al. 2019)

In India, along with air pollution, increasing sound levels is also a public health concern. Despite high noise levels, many people are not aware that it is hazardous to their health. Therefore, a survey was carried out to understand health risk perception among residents due to noise pollution. The way people perceive health impacts will help in mitigating noise levels.

\section{MATERIALS AND METHODS}

\section{Study Area}

A total of 10 sampling areas were identified for data collection, with five of them constituting rural fabric and five areas representing urban fabric. The five rural areas were villages chosen within a proximity of $5 \mathrm{~km}$. from XIM University, New Campus. Jamukoli and Niranjanpur are villages in Khordha District, whereas Kakudia, Bahelipada, and Harirajpur are in the Puri district (Fig. 1a). All five villages have agricultural operations throughout the year. Probable sources of noise pollution in and around rural areas include brick factories, mining and laterite stone cutting, sand mining, poultry, and movement of vehicles. Occasionally festive and private celebrations also contribute to the noise levels.

The five urban areas were identified in the urban fabric by determining different land use patterns, namely - commercial, residential, kerbside, mixed and institutional (Fig. 1b). Subsequently, for each location, six spatially spread points were identified for data collection, allowing for mapping a representative model. Palashpalli is a residential area close to the Biju Patnaik airport; Jagmara is an institutional area close to Khandagiri, a tourist place. Nuasahi is also a kerbside area close to National Highway 5. Mancheswar represents an industrial area with small and medium scale industries, automobile service stations. Fig. $1 \mathrm{a}$ and $1 \mathrm{~b}$ further depict the sampling locations in rural and urban areas.

\section{Noise Monitoring Equipment and Measurement Frequency}

The Phoenix Professional Sound Level Meter SM-10 was used for data collection. The instrument, once powered by 3 AAA batteries, provides a lifespan of 50 hours. It uses a $1 / 2$ inch electret condenser microphone that converts sound pressure levels to electrical signals, displaying them in decibels on a four-digit LCD module. The equivalent noise level (Leq) was calculated by estimating the average noise levels collected from a sampling location 4 times at an interval of 4 minutes. The monitoring at each location was carried out twice during the first and second rounds of sampling.

\section{Data Collection for the Spatial Distribution of Noise Levels}

The latitude and longitude readings on the sampling as described above were collected using a GPS device, the 'Garmin eTrex® 20x.'. The sampling was performed for ten days over two months during 2020 (February-March).

The 60 sampling locations (10 sampling locations monitored at six different points each) formed a baseline
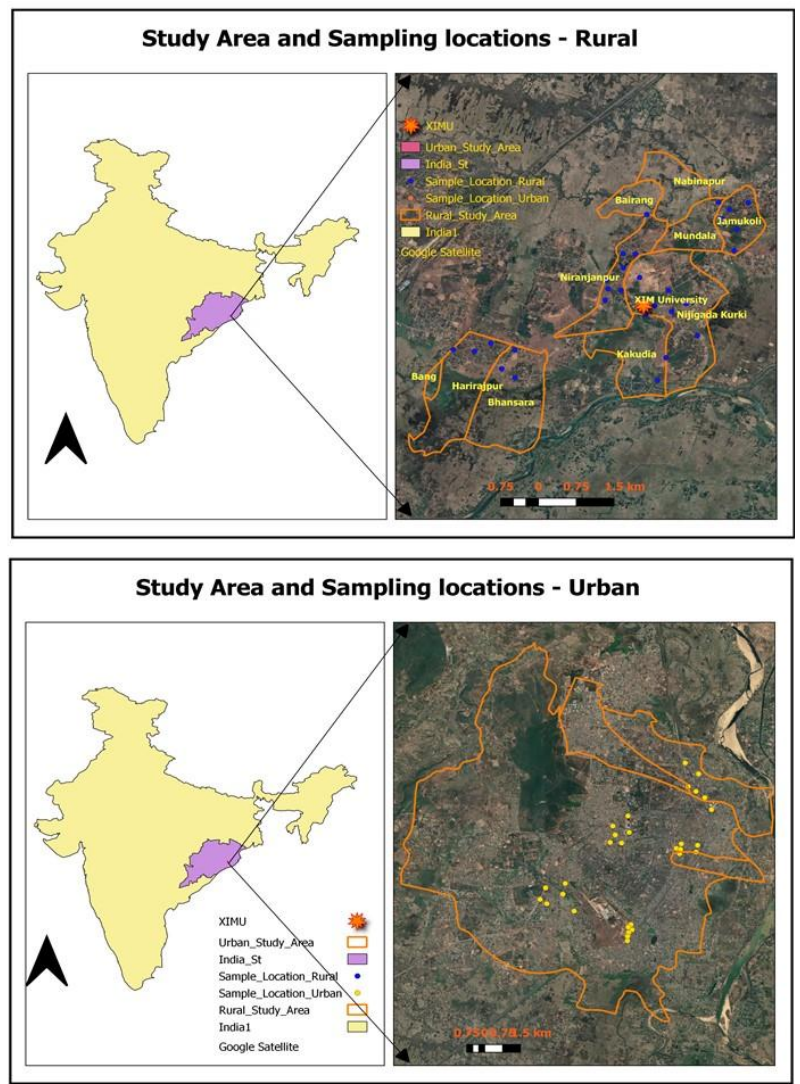

Fig. 1: Study area and sampling locations a) Rural area, b) Urban area. 
survey and were further analyzed using the Spatial Analyst extension of ArcGIS desktop. Kriging model was used to prepare a prediction output of noise levels. The prediction was further verified by generating a prediction error raster. The prediction error raster proved very useful in identifying the areas with maximum prediction errors, and thus a new set of 60 sample points were created for the second round of sampling. A remarkable reduction in prediction error was observed after the second round of sampling.

\section{Health Survey and Data Analysis}

A ground survey was also conducted to study the impact of noise levels on health. The nature of the survey was to collect door-to-door information based on five survey questions. The survey data was collected from the ground using a verbal interview. A total of 101 respondents were interviewed over eight days. An effort was made to collect data from at least ten responses from each study area using both the methods i.e., google form and personal interviews. The respondents were people of different ages and sex and were involved in different occupations. A questionnaire prepared by the Indic Society for Education and Development (INSEED), available in the public domain, was used to carry out a health survey (http://www.inseed.org/).

The data collected through the survey was analyzed using Microsoft Excel 2016. For spatial data analysis of noise levels, ArcGIS version 10.3 was used.

\section{RESULTS AND DISCUSSION}

This section presents the interpretations based on the descriptive statistical analysis of noise level data, spatial analysis using ArcGIS, and health surveys.

\section{Noise Levels At Rural Locations}

The Leq noise levels, calculated from average noise levels at five rural locations during the $1^{\text {st }}$ and $2^{\text {nd }}$ rounds of sampling, are discussed in this section.

\section{Sampling Round 1}

During this sampling period, the highest Leq noise level was observed at Harirajpur $(61.2 \pm 4.2)$. The reason for high noise levels at the Harirajpur location may be due to school, commercial activities, and stone mining activities carried out here.

For the Jamukoli region, the noise levels ranged between $52.1 \mathrm{~dB}$ to $61 \mathrm{~dB}$. The average noise level observed during this sampling round was $55.6 \pm 4.0 \mathrm{~dB}$. The lowest noise levels were reported at the Niranjanpur site $(50.6 \pm 5.5 \mathrm{~dB})$. At this site, the noise level varied between $46.4 \mathrm{~dB}$ to 58.2 $\mathrm{dB}$. These noise levels are lower than those reported recently (Pal \& Mandal 2021), near a stone mining and crushing area in the Dwarka river basin of Eastern India. The noise levels reported in their study were more than $85 \mathrm{~dB}$ from 6 am to $4 \mathrm{pm}$. The noise level ranged between $50.3 \mathrm{~dB}$ to $59.6 \mathrm{~dB}$ and $49.2 \mathrm{~dB}$ to $61.8 \mathrm{~dB}$ at Kakudia and Bahelipada sites. According to a study carried out at Shirdi in Maharashtra (Kankal \& Gaikwad 2011), the noise levels at the corner of the temple were observed to be in the higher range and found to be varying between 64.9 to $73.6 \mathrm{~dB}$. The respective average values at these two sites were $55.9 \pm 4.1 \mathrm{~dB}$ and 52.5 $\pm 4.9 \mathrm{~dB}$. The slightly higher noise levels at Kakudia can be attributed to sources like poultry farms, red-brick factories, cement factories, and sand mining activities. The descriptive statistics of noise levels reported during this sampling round is presented in Table 1.

\section{Sampling Round 2}

Unlike in the case of the first sampling round, during this sampling period, the highest Leq noise level was reported at the Kakudia site $(61.6 \pm 9.0 \mathrm{~dB})$. This probably can be attributed to increased activity at this location during the monitoring period.

The next highest average Leq values were reported at Niranjanpur $(57.1 \pm 12.9 \mathrm{~dB})$. Here, the noise levels ranged between $44.2 \mathrm{~dB}$ to $70.9 \mathrm{~dB}$. At Jamukoli, Leq noise values varied from $46.4 \mathrm{~dB}$ to $66.2 \mathrm{~dB}$ with an average value of 55.6 $\pm 6.8 \mathrm{~dB}$. The noise levels at Bahelipada were in the range of $44.3 \mathrm{~dB}$ to $72.7 \mathrm{~dB}$ with an average value of $54.3 \pm 12.2$ dB. Lastly, the lowest average noise levels of $53.0 \pm 10.2$ $\mathrm{dB}$ were reported at the Harirajpur site. The noise levels at this site varied from $43.4 \mathrm{~dB}$ to $67.3 \mathrm{~dB}$. This site showed

Table 1: Noise levels reported at rural locations during sampling round 1.

\begin{tabular}{|llllll|}
\hline Location & Jamukoli & Niranjanpur & Kakudia & Bahelipada & Harirajpur \\
\hline Minimum & 52.1 & 46.4 & 50.3 & 49.2 & 66.7 \\
Maximum & 61 & 58.2 & 59.6 & 56.3 & 61.2 \\
Average & 55.6 & 50.6 & 55.9 & 4.5 & 4.2 \\
Standard deviation $( \pm)$ & 4.0 & 5.5 & 6 & 6 & 6 \\
Count & 6 & 6 & & 6.1 & 6 \\
\hline
\end{tabular}

Note: All the values except count are expressed in $\mathrm{dB}$. 
the highest avg value in the first round. The descriptive statistics of noise levels reported during sampling round 2 is presented in Table 2.

\section{Noise Levels at Urban Locations}

The Leq noise levels, calculated from average noise levels at 5 urban locations, representing different land-use patterns during the $1^{\text {st }}$ and $2^{\text {nd }}$ rounds of sampling, are discussed in this section.

\section{Sampling Round 1}

During this sampling period, the highest Leq noise level was observed at Mancheswar $(81.3 \pm 6.6)$. The reason for high noise levels at this location maybe because it represents the industrial area with small and medium scale industries and automobile service stations etc. The noise levels varied between $69 \mathrm{~dB}$ to $87 \mathrm{~dB}$. In a study carried out in the two industrial areas of Kolhapur city in Maharashtra, India (Mangalekar et al. 2012), slightly lower noise levels were reported during the study period. The Leq noise levels were found to be varying between $70.3 \mathrm{~dB}$ to $79.3 \mathrm{~dB}$.

The next highest average Leq noise level of $79.6 \pm 14.8$ $\mathrm{dB}$ was reported at the Jagmara location. The high noise levels at this location can be attributed to the continuous movement of tourists and their tourist vehicles visiting this place. The noise level ranged between $60.6 \mathrm{~dB}$ to $98.6 \mathrm{~dB}$ at this location. Nuasahi site had an average Leq noise level of $74.2 \mathrm{~dB}$ which can be justified because it is a kerbside area near National Highway 5, which is characterized by a con- tinuous movement of vehicles. The minimum and maximum noise levels reported at this site were $62.9 \mathrm{~dB}$ and $87.7 \mathrm{~dB}$, respectively. Satyanagar site, representing the commercial and residential area, recorded an average Leq level of 70.8 dB. In one of the studies (Hunashal \& Patil 2012) a commercial cum residential area in the city of Kolhapur in the state of Maharashtra recorded Leq noise levels of $64.47 \mathrm{~dB}$. The minimum and maximum noise levels reported at this site are $63.4 \mathrm{~dB}$ and $80.2 \mathrm{~dB}$, respectively. Amongst all the urban sites, the lowest average Leq noise levels of $68.9 \pm 5.7 \mathrm{~dB}$ were reported at Palashpalli. These results can be justified by the fact that this is a residential site. This site's noise levels varied at this site from $61.9 \mathrm{~dB}$ to $79.2 \mathrm{~dB}$, which also might be attributed to its proximity to Biju Patnaik airport. The descriptive statistics of noise levels reported during sampling round 1 is presented in Table 3 .

\section{Sampling Round 2}

As observed in the case of rural locations, the highest average Leq values were observed at different locations than observed in the first round of sampling in urban locations. During this sampling round, the highest average Leq noise levels (75.2 \pm $10.2 \mathrm{~dB}$ ) were reported at the Satya Nagar site. At this site, the noise levels varied between $58.4 \mathrm{~dB}$ to $87.2 \mathrm{~dB}$.

The next highest average Leq noise levels were reported at Mancheswar $(69.6 \pm 13.9 \mathrm{~dB})$, being an industrial site. The minimum and maximum noise levels were reported to be varying between $45.5 \mathrm{~dB}$ to $88 \mathrm{~dB}$ at this site. Palashpalli site had average Leq noise levels of $68.8 \pm 12.3 \mathrm{~dB}$. The

Table 2: Noise levels reported at rural locations during sampling round 2.

\begin{tabular}{|c|c|c|c|c|c|}
\hline Location & Jamukoli & Niranjanpur & Kakudia & Bahelipada & Harirajpur \\
\hline Minimum & 46.4 & 44.2 & 44.1 & 44.3 & 43.4 \\
\hline Maximum & 66.2 & 70.9 & 70.2 & 72.7 & 67.3 \\
\hline Average & 55.6 & 57.1 & 61.6 & 54.3 & 53.0 \\
\hline Standard deviation $( \pm)$ & 6.8 & 12.9 & 9.0 & 12.2 & 10.2 \\
\hline Count & 6 & 6 & 6 & 6 & 6 \\
\hline
\end{tabular}

Note: All the values except count are expressed in $\mathrm{dB}$.

Table 3: Noise levels reported at urban locations during sampling round 1.

\begin{tabular}{|llllll|}
\hline Location & Palashpalli & Jagmara & Satya Nagar & Nuasahi & Macheswar \\
\hline Minimum & 61.9 & 60.6 & 63.4 & 62.9 & 89 \\
Maximum & 79.2 & 98.6 & 80.2 & 7.7 & 87.2 \\
Average & 68.9 & 79.6 & 70.8 & 6.2 & 6.6 \\
Standard deviation $( \pm)$ & 5.7 & 14.8 & 6.2 & 6 & 6 \\
Count & 6 & 6 & 6 & 6 & 6 \\
\hline
\end{tabular}

Note: All the values except count are expressed in $\mathrm{dB}$. 
maximum and minimum noise levels reported at this site were $50.6 \mathrm{~dB}$ and $84.2 \mathrm{~dB}$, respectively. At the Jagmara site, the average Leq noise level of $68.6 \pm 12.6 \mathrm{~dB}$ was reported. The minimum noise level at this site was estimated to be $46.7 \mathrm{~dB}$, while the maximum noise level was $85 \mathrm{~dB}$. The least average Leq noise level of $65.1 \pm 13.8 \mathrm{~dB}$ was recorded at the Nuasahi site. The minimum and maximum noise levels varied between $44.9 \mathrm{~dB}$ and $83 \mathrm{~dB}$, respectively. The descriptive statistics of noise levels reported during sampling round 2 is presented in Table 4 .

\section{Spatial Analysis of Noise Levels}

The data collected was spatially analyzed using ArcGIS desktops spatial analyst extension. Since the noise data was collected from different locations on land, it also qualifies that the data points were sampled from a continuous phenomenon in space. Kriging was used to generate a prediction model and a continuous raster. Continuous rasters are represented in Fig. 2a, 3a for rural areas and Fig. 4a, 5a for urban areas. The continuous prediction surface is useful for making educated
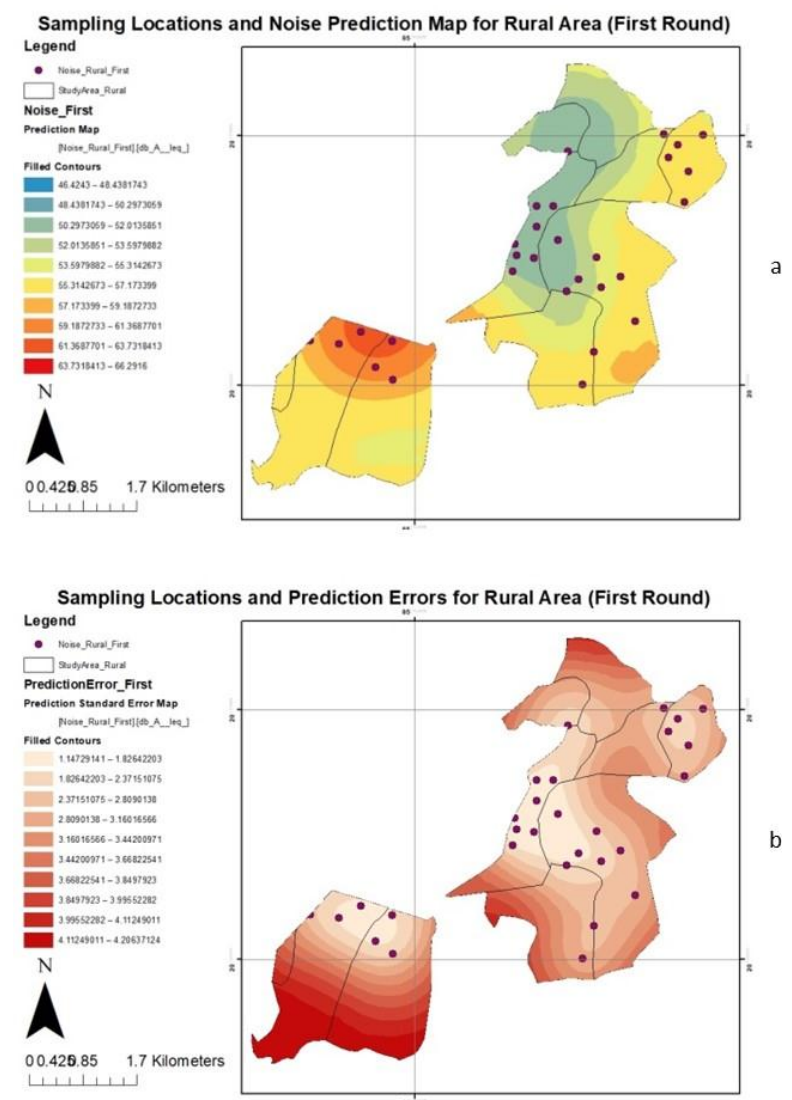

Fig. 2: Raster represents Noise levels in $\mathrm{dB}$ and prediction errors. a) Sampling locations and Noise level raster in Rural area, b) The prediction errors after Kriging applied on the sampling locations for rural areas. judgments, such as identifying regions where noise decibel levels are beyond the restrictions. Certain places have lower noise decibel levels as a result of land use patterns or other geographical factors.

However, this can stand true only when the predictions are accurate, and hence to check the prediction accuracy, prediction error maps were generated using the same set of data as shown in Fig. $2 \mathrm{~b}$ for rural areas and Fig. $4 \mathrm{~b}$ for urban areas. These rasters depicted in Figs. $2 b$ and $4 b$, show high prediction errors in certain areas. High prediction errors correspond to significant gaps/differences between actual values and the value generated by kriging.

In a rural setup, the prediction errors were higher on the boundaries of the study area, i.e. north and south. These areas were ignored in the first round of sampling as they were either part of agricultural fields or abandoned stone quarries (Fig. 1a). Also, as seen in Fig. 1a, the sampling locations are not equally distributed across the study area, causing higher prediction errors in the areas where sampling was not carried out. It is observed that the RMS value is more than one at
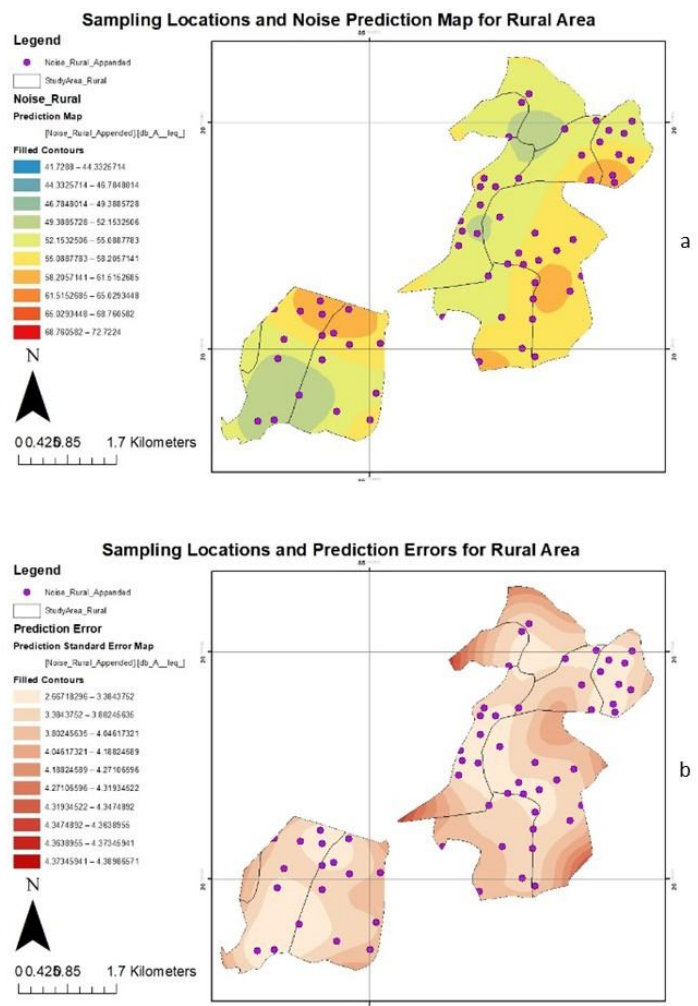

Fig. 3: Raster representing Noise levels in $\mathrm{dB}$ and prediction errors after the second round of sampling. a) Sampling locations and Noise level raster in Rural area, b) The prediction errors after Kriging applied on the sampling locations for rural areas. 
Table 4: Noise levels reported at urban locations during sampling round 2.

\begin{tabular}{|c|c|c|c|c|c|}
\hline Location & Palashpalli & Jagmara & Satya Nagar & Nuasahi & Mancheswar \\
\hline Minimum & 50.6 & 46.7 & 58.4 & 44.9 & 45.5 \\
\hline Maximum & 84.2 & 85.0 & 87.2 & 83.0 & 88 \\
\hline Average & 68.8 & 68.6 & 75.2 & 65.1 & 69.6 \\
\hline Standard deviation $( \pm)$ & 12.3 & 12.6 & 10.2 & 13.8 & 13.9 \\
\hline Count & 6 & 6 & 6 & 6 & 6 \\
\hline
\end{tabular}

Note: All the values except count are expressed in $\mathrm{dB}$.

all locations in the study area and goes up to 4.4 in some areas.

Thus, the second round of sampling in and beyond our study areas improvise the prediction accuracy on the fringes. The data from the first and second rounds of sampling is further appended, forming 62 locations to predict the noise levels in the rural area (Fig. 3a). The areas which bear an orange tone are those which see active transportation. Similarly, the areas represented by darker shades of green are open space/farmland. Xavier City Campus is represented as XUB on the map. Due to a larger population density, the noise levels are also high in the area. Noise levels at the rural
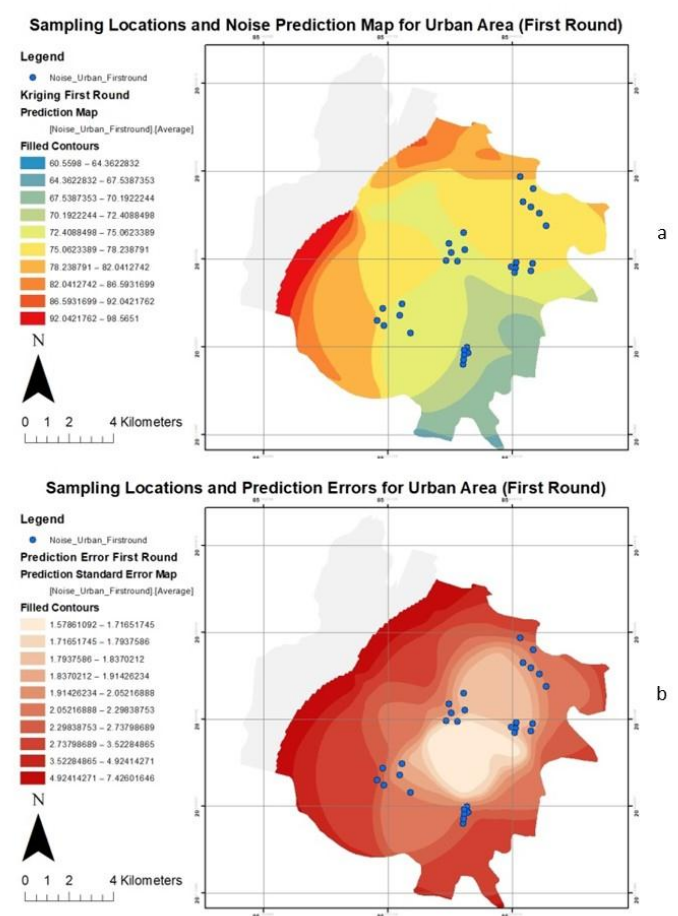

Fig. 4: Raster representing Noise levels in $\mathrm{dB}$ and prediction errors. a) Sampling locations and Noise level raster in the urban area, b) The prediction errors after Kriging applied on the sampling locations for urban areas. locations were under-regulated limits. Almost all the areas in the rural study area show error in the range of 2.6 to 4.1 (Fig. $3 b)$. Towards the edges of the study area, the error becomes significantly higher owing to a lack of representation.

However, in an urban area, the reason for high prediction errors was different. From Fig. 4b, it is seen that the sampling locations in the urban areas were clustered, resulting in better predictions near to the cluster and higher prediction errors farther from the cluster, especially in the northern region of the urban area. The northern area was initially not considered as the land use was dominated mainly by forest area (Fig. 1b). It is observed that the RMS value is more than one at all
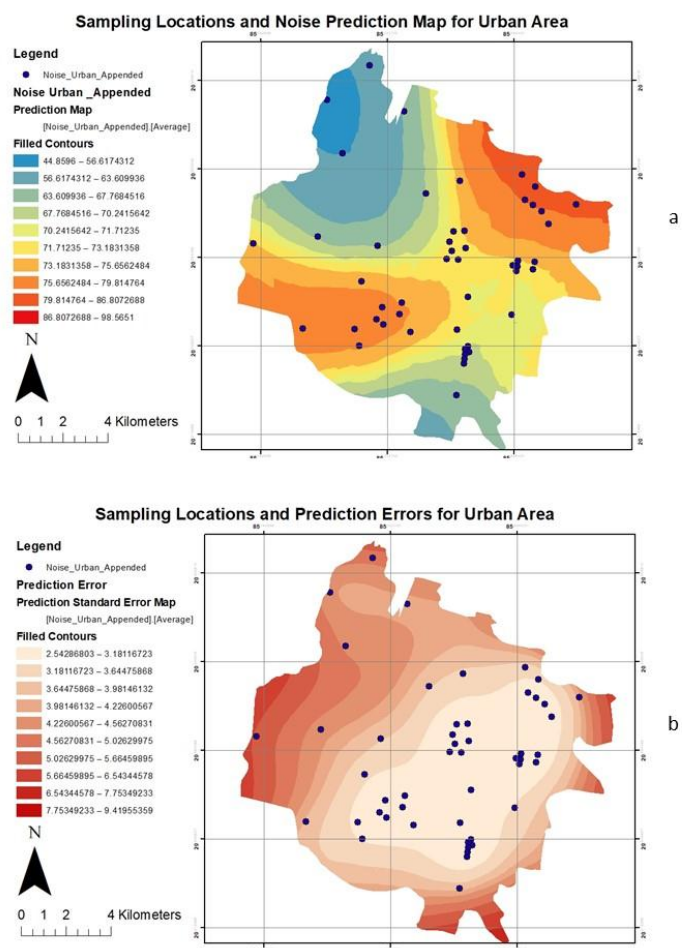

Fig. 5: Raster representing Noise levels in $\mathrm{dB}$ and prediction errors after the second round of sampling. a) Sampling locations and Noise level raster in the urban area, b) The prediction errors after Kriging applied on the sampling locations for urban areas. 
locations in the study area and goes as high as 7.4 towards the edges of the study area. It indicated the need for an increase in the sample points. Sampling data from the first and second rounds were appended together to get a prediction map and a prediction error map.

The prediction error model (Fig. 5b) shows a relatively low range of error (2.5 to 3.2) in the study area that is within the core city limit. The five localities identified within the city limit have higher predictability. This proves that attenuation of the $1^{\text {st }}$ and $2^{\text {nd }}$ rounds of samplings has led to better probability mapping and the map thus obtained has low errors. There can be two reasons for no substantial improvement in the prediction errors. The first is that the sample points in the first round of sampling were clustered, and hence appending them with the second-round sample dataset will not significantly improve the prediction accuracy. The second reason is that the study area is too large to be represented by 60 points. Hence, larger areas are recommended to create a fishnet overlay on the study area and use the centroid of the individual cells of the fishnet as the sampling locations.

As seen in the data records, Jagmara and Mancheswar Industrial Estate have the highest levels of sound pollution and are marked so in the prediction map. The city's center is defined by residential and mixed-use land patterns, with noise levels averaging 70 decibels. This is higher than the minimum requirements for industrial land use. Thus, using geo-statistics in this research not only provided an optimal prediction surface (prediction map) but it delivered a measure of confidence of how likely that prediction will be accurate (prediction error map).

\section{Health Survey Findings}

The survey findings revealed that $36.6 \%$ of respondents were unaware of the regulations about noise levels, as shown in Fig. $6 a$, while $13.9 \%$ of the respondents had merely heard of it from somewhere. This highlights a lack of awareness among the citizens. A probable reason is the higher rates of illiteracy in the village population $(50 \%$ of the villagers being villagers). Only $26 \%$ of the respondents were aware of such rules and regulations. More surprisingly, $45.5 \%$ of the respondents were not aware that noise pollution is a punishable offense (Fig. 6b).

Of the total respondents, only $36.8 \%$ of respondents said that noise pollution was an issue. More interestingly, 63.2\% of respondents said that they had no issue with noise pollution or were accustomed to the noise levels. The field data on noise levels showed that the sound levels in the city were much higher than the acceptable levels, irrespective of which these respondents did not find the levels to be polluting. This throws light that noise has become an inescapable part of modern life even though it causes nuisance and excessive noise has a negative physical and psychological impact on us. As shown in Fig. 6c, the people in the study area are habituated to the higher levels of noise in their surroundings. $42 \%$ of respondents said that transportation does contribute to high sound levels, and they felt that these sound levels were not a problem for them. Adding to that, $17 \%$ said that transportation does not cause harmful noise levels. $41 \%$ said that transportation causes noise pollution. The findings in the present study corroborated with the study conducted in Jharsuguda, Orissa found that people were unaware of the noise pollution effects though they experienced noise-induced symptoms such as headache, bad temper, hearing problem, loss of concentration, and sleep disturbance (Patel et al. 2006). The study by Hakzah et al. (2020) shows that

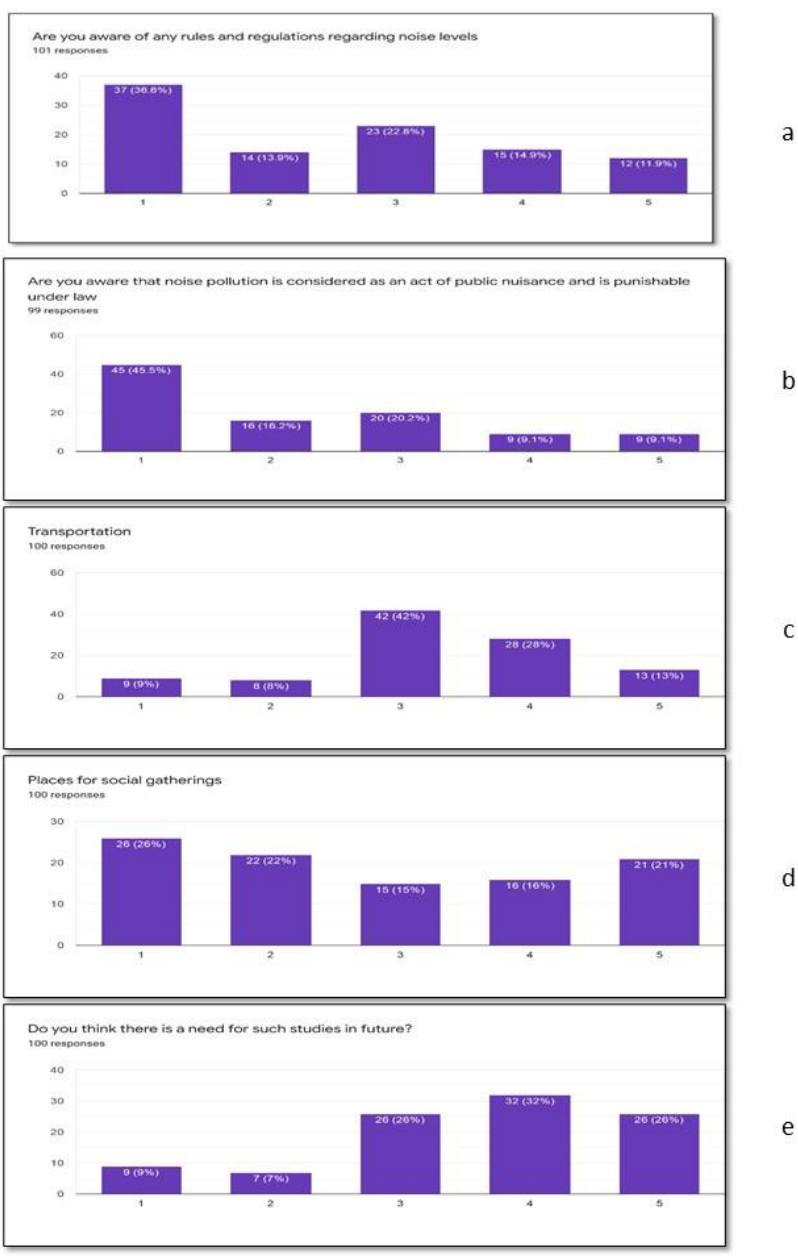

Fig. 6: Health Survey Response related to noise pollution a) Awareness of rules and regulations, b) Awareness of Noise pollution as a punishable offense, c) Perception of respondents related to noise pollution and transportation, d) Perception of respondents related to social gatherings as a source, e) Need for studies related to noise pollution in future. 
the impact of noise on public health by traffic on people who live around the road is a psychological disorder (80\%), physiological disorder $(35.7 \%)$, and the highest is a communication disorder $(84.3 \%)$.

India has a significant number of middle-class people, and with the increasing affordability of vehicles and loan schemes with manageable monthly installments, every household has a vehicle. As we go higher in the income groups, people prefer to have a personal vehicle for each household. This increases pollution levels and leads to vehicle congestion on the roads, meaning that people need to spend more time on the road. It directly affects the annoyance level/capacity of individuals traveling and leads to honking on congested roads and speeding on open roads.

During the survey, it was noticed that even the rural areas had seen a sharp increase in the number of vehicles and that almost every household in the village owns a two-wheeler. This has led to noise pollution within the cramped earthen roads of the village, and the number of accidents has also increased- something that was rarely experienced inside the villages even five years ago.

Our Indian culture is full of festivities. Every season is a festive season, and every occasion provides a reason to celebrate. Such celebrations involve the social gathering of people. Over the years, light and sound have become a symbol of expression and happening. So, these gatherings often consist of large music systems, which cause a significant amount of noise. As seen in Fig. 6d, a significant $37 \%$ of people agreed that social gatherings are a definite source of noise pollution. At the same time, $15 \%$ said that they were habituated to these high levels.

An exception to this is that due to the nature of the occasion, such high levels of noise are not considered annoying or polluting in nature. However, it does cause significant damage to humans and their surroundings. As per the study by Xu et al. (2020) living noise pollution which comes from entertainment activities, commercial activities, and other activities in people's daily life is considered most serious as it has the closest relationship with the acoustic environment of urban areas.

The following observations have been made while carrying out the survey:

i. Older adults experienced elevated heart rates when attending such events.

ii. If the magnitude of the noise is considered, social gatherings pollute more than transportation at any given time. However, it has more widespread acceptance.

iii. Any social gathering that uses a high-power speaker sys- tem needs to be permitted by authorities. The majority of respondents interviewed were not aware of this.

iv. In villages, people had complained that noise generated from these speaker systems damages their walls, and there have been cases where walls had collapsed when a procession that used speaker systems passed through their narrow roads.

Since noise levels are significantly high in the study areas, it is essential to establish the health effects on the people. In the present study, $27.7 \%$ of respondents agreed that changes in noise levels affected their sleep. At the same time, $12.9 \%$ of respondents said that they were accustomed to these noise levels.

Though noise levels may not physically harm, the degree of annoyance related to it can decrease comfort levels. Almost $21.8 \%$ of people agreed that noise levels lead to stress. Medical studies have established the link between stress and increased blood pressure, cardiovascular diseases, and the potential risk of stroke (Esler 2017). Many respondents in the current study also said that driving in traffic causes stress due to the constant honking and running of engines. Moreover, traffic congestion itself is a stressful site. As seen in Fig. 6e, $58 \%$ of people said that there was a need for studies on noise pollution in the future. This result highlights the essence of the survey and the need for the research.

\section{CONCLUSION}

This study focused on collecting noise level data from study areas located in both urban and rural setups. The recorded noise levels were much beyond the regulated limits in the Urban areas. In the rural areas, noise levels were lower yet were still beyond prescribed limits. The data thus collected suggested possible violation of The Noise Pollution (Regulation and Control) Rules, 2000. On spatially analyzing the data using ArcGIS, possible trends were seen in the variation of noise levels throughout the geography of the study area. The data was used to prepare a prediction model, which can be used to determine the noise levels at any given place within the study area. The purpose of the model thus created is to aid in developmental activities. The effort was also made to conduct a health survey to study the effect of this noise exposure. The study highlighted the lack of awareness regarding noise rules as applicable by law. The findings suggested a significant level of annoyance generated by the noise. The majority of the respondents said that the noise in their area was not tolerable and that further studies need to be conducted pertaining to this issue. This study like any other has its limitations. During the study, noise levels were recorded only during the daytime (6 a.m. to 10 p.m.) because 
of which the possibility of a 24-hour study was ruled out. The data was collected from specific locations and a maximum of 60 points was considered for data recording. It increased the spatial distance between the points and thus increased the error in the prediction map generated. Also, the time frame for data collection was limited to February and March. There was however uniqueness to the study as previously no such research has been believed to be completed for the area of concern.

To manage noise levels, a monitoring network needs to be established and increase green spaces as their ecosystem services are noise reduction (Dwevedi et al. 2018). Some of the additional measures that can be adopted to minimize noise levels are building noise barriers around highways, no honking awareness plans, responsible behavior in playing TV, radio, and musical instruments during festive celebrations. The overall aim is to improve the environmental quality and make the place more livable.

\section{ACKNOWLEDGMENTS}

The authors are thankful to the residents of Bhubaneswar and those of the neighboring villages of XIM University for providing us with their valuable inputs on noise pollution and health effects.

\section{REFERENCES}

Bisht, D.S. Smart cities: Testing ground for sensor-based instruments. 2020. Retrieved from https://www.downtoearth.org.in/blogger/digvijay-singh-bisht-90299 (Accessed on May 15, 2021).

Capetown, G. n.d. What Is Noise? Retrieved from https://www.capetown. gov.za/City-Connect/Report/Report-noise-pollution (Accessed on May 15, 2021).

CPCB. 2010. The Noise Pollution (Regulation And Control) Rules, 2000. http://cpcbenvis.nic.in/noisepollution/noise_rules_2000.pdf

Das, P., Talukdar, S., Ziaul, S., Das, S. and Pal, S. 2019. Noise mapping and assessing vulnerability in meso level urban environment of Eastern India. Sust. Cities Soc., 46: 101416. https://doi.org/10.1016/j. scs.2019.01.001

Dwevedi, R., Krishna, V. and Kumar, A. 2018. Environment and big data: Role in smart cities of India. Resources, 7(4): 1-10. https://doi. org/10.3390/resources7040064

Esler, M. 2017. Mental stress and human cardiovascular disease. Neurosci. Biobehav. Rev., 74: 269-276. https://doi.org/10.1016/j.neubiorev.2016.10.011
Garg, N., Sinha, A.K., Dahiya, M., Gandhi, V., Bhardwaj, R.M. and Akolkar, A.B. 2017. Evaluation and analysis of environmental noise pollution in seven major cities of India. Arch. Acoust., 42(2): 175-188. https:// doi.org/10.1515/aoa-2017-0020

Hakzah, P.A.I., Nasir, N. and Hamzah, S. 2020. The effect of traffic noise on public health. Enferm. Clinica, 30: 249-253. https://doi.org/10.1016/j. enfcli.2020.06.057

Hunashal, R.B. and Patil, Y.B. 2012. Assessment of noise pollution indices in the city of Kolhapur, India. Procedia - Soc. Behav. Sci., 37, 448-457. https://doi.org/10.1016/j.sbspro.2012.03.310

Jain, R.K., Cui, Z. and Domen, J.K. 2015. Environmental Impact of Mining and Mineral Processing: Management, Monitoring, and Auditing Strategies. Elsevier Inc, The Netherlands. https://doi.org/10.1016/ C2014-0-05174-X

Jamir, L., Nongkynrih, B. and Gupta, S.K. 2014. Community noise pollution in urban India: Need for public health action. Indian J. Community Med., 39(1): 8-12. https://doi.org/10.4103/0970-0218.126342

Kankal, S.B. and Gaikwad, R.W. 2011. Studies on noise and air quality monitoring at Shirdi(Maharashtra), India. Adv. Appl. Sci. Res., 1(2): 63-75.

Khaiwal, R., Singh, T., Tripathy, J.P., Mor, S., Munjal, S., Patro, B. and Panda, N. 2016. Assessment of noise pollution in and around a sensitive zone in North India and its non-auditory impacts. Sci. Total Environ., 566-567: 981-987. https://doi.org/10.1016/j.scitotenv.2016.05.070

Khatik, V.A., Intarak, R. and Foto, T.G. 2019. Development and mapping of noise risk zones in neighbourhoods along Saensaep Canal: revealing the public health burden of water transport in Bangkok. Nat. Env. Poll. Tech., 18(2): 645-650.

Mangalekar, S.B., Jadhav, A.S. and Raut, P.D. 2012. Study of noise pollution in Kolhapur City, Maharashtra, India. Online, 2(1): 65-69.

Olayinka, O.S. 2013. Effective noise control measures and sustainable development in Nigeria. World J. Environ. Eng., 1(1): 5-15. https:// doi.org/10.12691/wjee-1-1-2

Pal, S. and Mandal, I. 2021. Noise vulnerability of stone mining and crushing in Dwarka river basin of Eastern India. Environ. Develop. Sustain., 12: 1-22. https://doi.org/10.1007/s10668-021-01233-2

Patel, R., Tiwari, T.N. and Patel, T. 2006. Noise pollution in residential areas of Jharsuguda Town, Orissa (India) and its impact. J. Environ. Sci. Eng., 48(3): 209-212. https://pubmed.ncbi.nlm.nih.gov/17915786/

WHO. n.da. Noise - Data and statistics. Retrieved May 15, 2021, from https://www.euro.who.int/en/health-topics/environment-and-health/ noise/noise

WHO. n.db. Noise - Data and statistics. Retrieved May 15, 2021, from https://www.euro.who.int/en/health-topics/environment-and-health/ noise/data-and-statistics

Xu, C., Yiwen, Z., Cheng, B., Li, L. and Zhang, M. 2020. Study on environmental Kuznets Curve for noise pollution: A case of 111 Chinese cities. Sust. Cities Soc., 63, 102493. https://doi.org/10.1016/j.scs.2020.102493

Yuan, M., Yin, C., Sun, Y. and Chen, W. 2019. Examining the associations between the urban built environment and noise pollution in high-density high-rise urban areas: A case study in Wuhan, China. Sust Cities Soc., 50, 101678. https://doi.org/10.1016/j.scs.2019.101678 